\title{
Implementation of the Technological Competence of Future Specialists
}

\author{
Sh. U. Kosimov ${ }^{1}$, M. R. Rafiqova ${ }^{2}$, M. I. Murodova ${ }^{3}$ \\ ${ }^{1}$ Deputy Director of Termez Branch of TSPU Named After Nizami, Termez, Uzbekistan \\ ${ }^{2}$ Teacher of Higher Military Customs Institution, Tashkent, Uzbekistan \\ ${ }^{3}$ Teacher of Termez Branch of TSPU Named After Nizami, Termez, Uzbekistan \\ Email: beauty.of.heart@mail.ru,muattar.ravshanova@bk.ru,mukaddas.murodova@bk.ru
}

How to cite this paper: Kosimov, Sh. U., Rafiqova, M. R., \& Murodova, M. I. (2021). Implementation of the Technological Competence of Future Specialists. Creative Education, 12, 666-677.

https://doi.org/10.4236/ce.2021.123046

Received: January 16, 2021

Accepted: March 26, 2021

Published: March 29, 2021

Copyright (c) 2021 by author(s) and Scientific Research Publishing Inc. This work is licensed under the Creative Commons Attribution International License (CC BY 4.0).

http://creativecommons.org/licenses/by/4.0/

\begin{abstract}
The article deals with the problems of developing the technological competence of future teachers. It contains definitions of the concepts of competence and technological competence, provides an overview of the history of entry into education and the current level of relevance. Providing close cooperation between vocational education and production, improving the quality of vocational education, and continuous improvement of the educational process is an urgent task for reforming the system of professional education, training personnel capable of actively and effectively participating in the process of its sustainable growth and modernization. In the lesson of preparation for the profession, students acquire the skills, abilities, competencies, and the competence of interdependence. From a pedagogical point of view, competence is interpreted as a combination of the knowledge, skills and experience of individuals with specific social and professional status to the extent of the complexity of the tasks and problems they perform. Suitable for the competence approach we are considering is the "competence" and "jurisdiction", which differ in each other. The article describes the objectives of continuous improvement, effectiveness, and adaptation of the content of professional education, as well as the components of practical professional education.
\end{abstract}

\section{Keywords}

Technological Competence, Pedagogical Process, Methods, Knowledge, Information

The Decree of the President of the Republic of Uzbekistan dated February 7, 2017. PF-4947 "On the Strategy of Action for the Further Development of the Republic of Uzbekistan for 2017-2021" is now implemented and aims at full 
coverage of the social sphere (The Decree of the President of the Republic of Uzbekistan, 2017: p. 112).

A separate section of the Decree focuses on the social development priorities, with particular emphasis on the development of science and education (The Decree of the President of the Republic of Uzbekistan, 2017: p. 113).

It outlines the tasks for radical reform of the sector and the gradual resolution of urgent problems that need to be addressed.

In our opinion, the concept of technological competence determines the attitude of teachers of vocational education to their professional activities. Technological competence has deep roots in the theory and practice of pedagogy, so this competence plays a critical role in preparing specialists for future professional teaching delivery in higher education. Training of competitive and qualified specialists in the various disciplines of higher education in academic institutions operating in the Republic is an important requirement of the time, and it is paramount to use all available opportunities. Technological competence is the basis of knowledge, skills and abilities in technology. We can improve the quality and effectiveness of our higher education system by introducing international academic assessment standards. Also, we can improve the efficacy of our educational system by a continuous adaptation of the content matter of professional and practical education to meet these standards.

\section{Vocational and Professional Education: Definition of Terms}

The basis of the vocational education process is the interdependent professional knowledge, skills, and competences provided by teachers and practice leaders in the vocational education process and mastered by students in the professional learning process (Avazov Sh. et al., 2014: 22 b).

"Knowledge is the information that people generate about the phenomena of nature and society, the reflection of reality in human thinking" (The National Encyclopedia of Uzbekistan, 2002a: p. 704). Knowledge is a system of concepts learned about theoretical, practical and applied activities that are remembered, accepted, and taken into account (Khodzhaboev \& Kosimov, 2007: 4 b).

This definition also applies in the general sense to the notion of "professional knowledge". Professional education is the information necessary for the professional activity of a specialist. The result of professional cognitive activity of the student in the course of professional education is the acquisition, systematization and consolidation of the concepts of professional laws and methods of work.

"Skill is the ability of a person to carry out a particular activity or action based on past experience" (The National Encyclopedia of Uzbekistan, 2002b: p. 182).

Professional skill is the ability of a specialist to apply the acquired knowledge in his or her work in non-standard, unusual and complex situations; the process and the result of consciously executing his/her professional activities with a quick, economical, correct, less physical and mental effort. In other words, a 
professional skill is a way of performing practical actions based on the professional knowledge that a specialist has such as the ability to focus on working conditions, use necessary techniques and readiness to take action to solve tasks. Professional skills can be classified into the following levels: 1) elementary skills; 2) intermediate skills; 3 ) complete skills.

Elementary skill is the ability of a future specialist to perform small business operations on the basis of professional knowledge acquired in theoretical classes.

Intermediate skills is the ability of a future specialist to perform practical actions by repeating exercises over and over again, to target in a work environment, to use the necessary techniques, and to perform a task.

Complete skill is the ability to do work in a professional way, and this ability becomes a skill.

"Qualification is a profession that is acquired through good work" (The National Encyclopedia of Uzbekistan, 2003: p. 419).

Professional qualification is the ability of a junior specialist to carry out specific professional activities; automation of individual components of professional activity; a way of working that has become a habit as a result of the repeated repetition and training of professional skills. When the level of automation of the working process is higher, the qualification also should be higher.

Professionalism is the acquisition of a specific type of professional activity at a high and ever-increasing level, characterized by the superior quality of work, elevated labor productivity, professional independence, the culture of work and creative attitude to work.

\section{Competence and Higher Education}

First of all, it is necessary to clarify the essence of the categories that define the meaning of competence and answer the following questions:

1) How does a competent approach differ from a science-based approach to knowledge, skills and competencies?

2) What changes should be made to the organization of the learning process (its forms and methods) to help identify the competence of learners?

The word "competence" (its roots are Latin competens-that is, compliant) has two meanings in its semantics: 1) profound knowledge; 2) competent, aware of news in a particular area (Latin Dictionary and Grammar Resources, 2021). In pedagogy, the word competence (Latin competere-achievement, conformity, conformity) is defined as the range of knowledge and experience that a person possesses and is reinforced in job descriptions or other normative documents. In the pedagogical dictionary, "competence" is an individual's level of education, determined by the degree of comprehension and use of theoretical tools of cognitive or practical activity (Kosimov Sh. U., 2018: 166 b).

There are two options for interpreting the proportions of the terms "competence" and "jurisdiction" where they are either identified or differentiated. Under the first option, competence and jurisdiction are defined as follows: 
1) Knowing something is good and effective. 2) Compliance with job requirements. 3) Ability to perform specific job duties. In this case, the term "competence" is often used to describe it. In the context of such identification, it is noted that the practical orientation of the competence approach is much broader-competence is an area of relationship between knowledge and action in human practice.

The second option of interpreting the proportions of "competence" is to use competencies as a system that influences the use of thinking, knowledge, skills, and as well as the processes that underlie human experience.

\section{Teachers in Higher Education}

Contemporary instructors are well-educated and capable of using modern techniques and technologies. To fulfill their role in society and productively instruct future generators of students requires them to be well trained to deliver quality teaching in higher education institutions. Educators are crucial elements that reflect the current social, innovative, and political realities of society. Teachers can create educational environments where all learners feel they are part of a community through their social actions. In the rapid development of society, there is a growing need for educators with special knowledge of socio-political issues. Outstanding educator's readiness for professional activities is evidenced by the fact that they are mature with a good comprehension of special knowledge, professional teaching activity, and social relations. Part of an exceptional teacher's strength is the acquisition of multi-component knowledge, skills, and abilities to provide creative learning activity on the informational design and the educational process. Another strong teaching ability is the development of logical analysis of teaching materials, integration of interdisciplinary activities, student engagement, and independence.

\section{Education, Industry and Technology}

To shed light on the very essence of technological competence, we need a look at the history of its emergence in pedagogy. This exploration requires that we examine and analyze element of its emergence. The concept of technology was rarely used in pedagogy and didactics until the 50s. Traditional pedagogy and didactics challenged the concept of industry and industrial "technology" in explaining the essence of creative and psycho-pedagogical, educational and educational processes. The reason is that the notion of technology is the result of rapid development in the main field of technology.

Technology in manufacturing is a system aimed at obtaining products with quantitative and qualitative characteristics that result in predetermined performance using the proposed algorithms, methods and tools. For this reason, until recently, the concept of "technology" has been used mainly to describe processes in industry and production. People in manufacturing were mainly employed with industrial equipment, raw materials, labor tools and semi-factories and 
parts.

In production facilities, with the use of technology, equipment and tools were placed in the workshops in accordance with the established procedure. At the same time, effective methods of transferring raw materials to production lines were developed, as well as calculations on production of high quality products at low cost, which is called the technological process.

Therefore, the technological process determines the sequence of operations performed under specific conditions using the necessary tools and materials. In the book The Great Didactics Y. A. Komensky comments on the technologization of the educational process. An important task of the theory of education is to "teach everybody, while teaching that "only in the case of success, failure should not occur" (Komensky. The Great Didactics. library.ziyonet.com).

One of the main ideas of technology is the notion that the result is guaranteed. Y. A. Komensky called the result-learning mechanism, the learning process a "didactic machine". In shaping the learning process for the full performance of a "didactic machine" (Komensky. The Great Didactics. library.ziyonet.com) with high results in education, it is necessary to create the following:

- Educational objectives;

- The tools needed to achieve these goals;

- Rules of use of existing means.

As a result, based on the specific goals and means of use, a module is being developed that is now widely used in education. Present-day employers pay great attention to the following qualities when hiring teachers:

- Independent thinking, that is, the ability to apply the acquired knowledge in the process of solving various social problems;

- Creative thinking;

- High vocabulary based on extensive knowledge of social events.

It is important to note that the following qualities must be present in order for a graduate of today's university to have a place and social status in society:

- Be able to quickly and painlessly adapt to changing life situations, independently acquire the knowledge they need and apply it effectively to solve various problems;

- To think independently and critically, to foresee possible problems in real life;

- To effectively solve problems using modern technologies and techniques, to generate new ideas, to present ideas, and creative thinking;

- Be able to quickly communicate with members of different social groups, work in various areas of life, and prevent or avoid harmful situations;

- To work continuously to enhance their intellectual, professional, spiritual and educational potential.

\section{Teaching, Technology, and Competence}

As we consider the formation of technological competence of future professional education teachers, we must first focus on the meaning of the terms "technolo- 
gical" and "competence". Since the concept of technology comes from the word scientific knowledge, and currently there is no single definition in education, the following definitions are often used:

- Technology (Greek techno-skill + logos-learning) skill-a set of knowledge, including production tools and methods to change the quality of the processed object;

- In the pedagogical dictionary-reference is a set of methods used in technology, in any field, culture or , any business;

- Technology-oriented system for obtaining products with definite qualitative parameters, which results in predetermined results using algorithms, methods and tools proposed by science.

The analysis of the pedagogical and psychological literature shows that the concepts of competence and professionalism are combined through the abstractions of technological skills and competence. The concepts of "competence", "jurisdiction" and base competence are widely used when discussing educational issues of a new quality due to the change of competency-focused approach to education. There is an active discussion among educators about a deeper understanding of what competence and jurisdiction are, and which of them is more important. A number of studies are currently underway to formulate and evaluate these concepts and to clarify the above definitions. For this reason, these concepts still have different definitions and interpretations.

The concept of "competence" and "jurisdiction" has been widely used in the fields of management theory, occupational psychology, labor organization, and professional practice since its inception. Due to these different theoretical approaches, various interpretations of the above terms were formed. It should also be noted that the words "competence" and "jurisdiction" are not synonymous. The word "competence" (Hutmache, 1997) (in Latin, compete "meet together, meet the requirements, match") has two meanings:

- Something that someone has learned so well;

- The rights and powers of somebody.

Competence means being proficient in two ways. According to the literature, "competence" has been developed and widely used by the scientific theory of labor organization and management. According to the dictionary competence means: having a thorough knowledge of the work, the meaning of the work, the ways and means to achieve the goals, and the appropriate skills and abilities to complete these goals (Hutmache, 1997).

Competence comes from a competency-based approach to education. In this approach, educators who can carry out effective teaching strategies and activities are competent. In modern management models, there are three levels of competence:

- Integrative competence-the ability to integrate and complement each other's skills in the context of rapid change in life events;

- Socio-psychological competence-to have extensive knowledge and skills in understanding human qualities, motivating their activities, having high com- 
municative culture and empathy;

- Management competencies in decision-making activities, data collection methods, work with people, etc.

The new concept of social-education gave impetus to its accelerated development. The first aspect of social-education is the development of technological competence. This development is related to the expansion of the range of competitors' organizers, and it is one of the most important factors for professional practice. The second aspect is the development of teaching competence. This development is related to a competency approach to learning from the early stages of education and a deep understanding of the importance and necessity of its implementation (Hutmache, 1997).

In our national pedagogy, the concept of competence has been used as an educational category since the second half of the 1970s. At the same time, the level of professional competence determines a certain level of professional knowledge, skills, and personal qualities that are required in the traditional range of teaching activities (Hutmache, 1997).

Many teachers and psychologists have addressed the problem of educationoriented competence. In their work, several aspects of a competency-based approach to education have been explored and identified. The main part of scientific and pedagogical researches in the field of competence-oriented professional education is focused on the problems of training and continuing the development of pedagogical staff (Kosimov Sh. U., 2018: 168 b).

Psychological-pedagogical analysis of research on this issue shows that no single approach to the concept of the pedagogical meaning of the concept of "competence" and "jurisdiction" has been developed so far. Pedagogical scholars have identified and developed the competencies and components of the competence needed to cover this phenomenon in a broader context (Kosimov Sh. U., 2018: 169 b).

Specifically, S. Shishov (Shishov, 2000: p. 206) introduced the following definition of competence in pedagogy:

- General skills based on the acquired knowledge, experience and values based on learning,

- The ability to link the existing knowledge to the existing problems by providing links between existing information and the current situation.

According to P. V. Simonov and others, competence is the ability to act based on the acquired knowledge (Simonov, 1984). In contrast to the knowledge, skills and abilities acquired when working with reference samples, competence allows independent functioning obtained with the help of universal knowledge. The use of knowledge and skills in the form of competence-social practices impact educational outcomes. When educators meet socio-cultural and community-based demands, they impact positively on learning outcomes.

Consequently, competence is the result of an action and ability, willingness, or ability. In other words, competence is a category reflected in the professional, social, or other activities of a subject, which intend to solve a particular problem. 
Generally, the degree of competence is measured by the degree of competently formed skills.

\section{Competence and Professionalism}

A. M. Novikov considers competence to be a professional concept. Novikov noted that when assessing the business qualities of people, the term "professionalization" is used instead of "professionalism." In his view, the first concept concerns technological training. The second is the ability to work independently, be creative in any business, continually update knowledge, be broad-minded, have open discussions, reason about economically feasible systems, work in a team, and communicate with colleagues. These concepts are components of the qualification base and a professional nature. Novikov noted that the competence of modern specialists is also assessed through their knowledge of outsiders, information and communication technologies, environmental and economic information, and marketing in their field (A. M. Novikov \& D. A. Novikov, 2013).

A. K. Markova believes that a person's competence may be on a lower level than their professionalism. A.K. Markova states "A person may achieve professionalism in his or her field of activity, but may not be competent in dealing with all professional problems" (Markova, 1993).

Certain objective conditions are required to reach the potential competence of an individual as an effective professional. These conditions are the appropriate motivation, the will of the person, and the actualization of the acquired knowledge. We can use the term "competence" to define "professionalism" and "excellence" because a person has the potential to bring a representation of "professional competence" to science.

Analysis of the sources shows that competence can be used in two main directions. Professional competence in precise thinking is a set of indicators that a person needs to implement his professional skills.

From this perspective, professional competence can analyze labor and technological processes, technical tasks and documentation, eliminate errors in the work process, meet technological requirements, acquire additional skills, have a high culture of the work process, , and promptly eliminate errors in technological processes. Professional competence is required, based on the professional qualities of a person who has such elements

In a broad sense, professional competence as a synonym for the word "competence" depends on an individual's professional activity. Thus, covering all aspects of professional competence is necessary for the effective functioning of a person. This reflects the fact that professional competence is a multi-component product with many constituents.

\section{Discussion}

The effective functioning of the education system, the development, and implementation of advanced forms and methods of teaching, the achievement of high 
performance by students are all directly related to well-developed science and technology techniques. Currently, there is a need to improve the professional qualities of teachers, develop key elements of education, update its content, and promote innovation in the field of technology. However, teachers are technologically unprepared, so it is difficult to meet educational standards using nontechnological methods. There must be a clear understanding of the differences between technology and methodology

Analyzing the roots of technological competence and the current state of theory and practice, the development of education can be conditionally divided into two stages (Kosimov, 2018: 165 b):

- Methodical;

- Technological.

There are no clear boundaries between these stages, since they are procedurally complementary, enriched and enriched in the process of development, as well as education that is unbiased in the comprehensive training of teachers. Depending on the methodology and technology, competence can be divided into two types:

- Modern competence;

- Technological competence.

There are no clear boundaries between these stages since they are procedurally complementary, enriched, and enriched in the process of development, as well as education that is impartial in relation to the comprehensive training of teachers. Depending on the methodology and technology, competence can be divided into two types:

- Modern competence;

- Technological competence.

These are important forms of competence. Reflexology research of the last 20 - 30 years can be seen in pedagogical technologies. "Pedagogical Technologies" and the term "pedagogical technique" were also used during this period as a set of tools and methods necessary for the effective organization of the educational process (Kosimov, 2018: 165 b).

Technical means of education over the past four decades (40 - 50 years).

As a result of its rapid development, the concept of "teaching technology" arose, which subsequently became increasingly called "pedagogical technology". According to V.V. Ilin, in the mid-60s, there were two directions in pedagogical technologies (Ilin, 1989).

The first direction was "technologies in education", based upon the technical aspects of teaching, and the use of software training carried out in various forms. The second direction was "technology of education" or "technology of educational process". "Technology of education" is directly linked to the organization of the process. In the 1970s, scholars in many countries focused on modernizing teaching equipment and improving teaching aids, which were considered an important pedagogical condition for effective teaching. 
In 1977, the International Workshop on Educational Technologies in Budapest identified the key features of technological processes in education. These features included:

- Being well versed in the use of technical means in education;

- Availability and thorough knowledge of audiovisual materials;

- Having a methodology for the rational use of the above factors.

Computerization in all areas, since the 1980s, has not gone beyond education. Since that time, the concept of "pedagogical technologies" has appeared. Until the 1990s, there was an objective accumulation of technological knowledge related to technical development and various interpretations of technological concepts. Despite several scientific studies, the social nature of educational technologies is still not fully understood. Nonetheless, technology and pedagogical processes have become more prominent in education than traditional education. These trends have demonstrated the potential to address existing educational problems more quickly. By the beginning of the third millennium the technology and designing of educational processes and systems aimed at solving technological and pedagogical problems of education were tested.

It combines designing of a general education system and professional training, along with the development of technology and didactic tools and techniques for teaching staff to enhance the pedagogical culture, and optimize the educational process.

It is well-known that the state and development of pedagogical systems in each period creates terms that reflect the methods, technologies and tools of the period.

Inadequate coverage of technological and pedagogical concepts and terminology creates a most burdensome situation for teachers, which sets the task of creating a comprehensive, systematic understanding of the procedural and content of technological competence and the formation of categorical devices of pedagogical technology.

It is incorrect to directly link the technological approach to education with the technicalization of society, as the education component plays an important role in the training of teachers and the formation of the younger generation. From ancient times to the present, the collaborative effort between the teacher and the pupil is based on philosophical ideas that serve to realize individual capabilities.

From the earliest stages, pedagogy has always been directly linked to the interpretation of human essence and its individuality, as it is shaped by the pursuit of universal philosophical ideas. After all, all philosophical ideas form the basis of pedagogy. They serve to educate a person as a fully developed personality.

Technology for the formation of educational processes develops projects for teachers and educators for setting goals for self-realization and implementation, managing harmonious links between internal and external plans of activity: a combination of universal and unique personal capabilities.

The introduction of personality-oriented characteristics to the notion of 
competence emphasizes that there is an indication that teachers have notable qualities, such as self-education, self-change, self-improvement, and self-management.

This process is more effective as a result of the formation of intellectual activity and technological competence. The features of the technological phase are reflected in the support and harmonization of the intellectualization processes of the subjects of educational activities. It can be understood that the transfer of pedagogical culture and social experience from migration functions to functions of human education.

According to the requirements of technology, the following are the characteristics of technological competence:

- Correspondence of technological support (methods and means of the organization of educational activity);

- Control of the processing of the acquired knowledge;

- Increasing role of pedagogical activity;

- Duplication of pedagogical technologies;

- Transfer, transfer of pedagogical experience;

- Guaranteed results.

Currently, three levels of competence are recognized, minimal, medial, and complete. Based on this, the combination of these three levels can produce a competence formula: minimum (cognitive mobility) + medial (flexibility of methods) + complete (critical thinking).

A technological point of view has deepened the competence framework:

"Knowledge mobility" should rely on the professionalism of pedagogical invariants.

"Matching methodology" means that the organization of activities is realized through the development of unique components based on technology and cybernetic models.

"Critical thinking" teaching can be considered to be based on strict technological and axiological requirements.

\section{Conclusion}

Based on the information and ideas presented, the technological competence of the teacher of professional education can be considered as a list of creative and technological knowledge, as well as the capability of measuring activities for the renovation of pedagogical realities.

Technological competence is a modern system of training and education, which is based on the invariant basis of mechanisms and tools, mechanisms and tools for the development and integration of elements.

\section{Conflicts of Interest}

The authors declare no conflicts of interest regarding the publication of this paper. 


\section{References}

Aminov, M., Akhmedov, B. et al. (2002a). The National Encyclopedia of Uzbekistan. In the 3rd Year. Hydrophilia-Zebras (704 p.). T.: State Scientific Encyclopedia of Uzbekistan.

Aminov, M., Daminov, T., Dolimov, T. et al. (2002b). The National Encyclopedia of Uzbekistan. In the 4th Year. Konimech-Mirzokush (704 p.). T.: "National Encyclopedia of Uzbekistan" State Scientific Publication.

Aminov, M., Daminov, T., Dolimov, T. et al. (2003). The National Encyclopedia of Uzbekistan. In the 5th Year. Konimech-Mirzokush (704 p.). T.: The National Encyclopedia of Uzbekistan, State Scientific Publishing House.

Avazov, Sh., Muslimov, N., Kosimov, Sh., Khodiev, U., \& Avazov, E. (2014). Methods and Technologies of Practical Professional Training (in Objects, Tables and Pictures) Methodical Manuals in Professional Colleges (300 p.). Tashkent: NAVROZ.

Hutmache, W. (1997). Key Competencies for Europe. Report of the Symposium, Berne, 27-30 March 1996, 106-107.

Ilin, E. N. (1989). The Art of Communication. In Pedagogical Search (223 p.). M.: Prosveshchenie.

Khodzhaboev, A. R., \& Kosimov, Sh. (2007). Methodology of Organization and Implementation of Practical Professional Education. In A Training Manual for Special Subjects and Vocational Colleges in the Vocational Colleges (148 p.). T.: Inc. Economics.

Komensky. The Great Didactics. library.ziyonet.com.

Kosimov, Sh. U. (2018). Development of Methodological Bases of the Organization of Practical Professional Training in Professional Colleges (165 b.). PhD Diss., T.: CALCULATION.

Kosimov, Sh. U. (2018). Development of Methodological Bases of the Organization of Practical Professional Training in Professional Colleges (166 b.). PhD Diss., T.: CALCULATION.

Kosimov, Sh. U. (2018). Development of Methodological Bases of the Organization of Practical Professional Training in Professional Colleges (168 b.). PhD Diss., T.: CALCULATION.

Kosimov, Sh. U. (2018). Development of Methodological Bases of the Organization of Practical Professional Training in Professional Colleges (169 b.). PhD Diss., T.: CALCULATION.

Latin Dictionary and Grammar Resources (2021). Latin Definition For: Competens, (gen.), Competentis.

http://atin-dictionary.net/definition/11686/competens-gen-competentis

Markova, A. K. (1993). Professional Competence of the Teacher. In A. K. Markova (Ed.), Psychology of Working Teachers: Book for the Teacher. M.: Prosveshchenie.

Novikov, A. M., \& Novikov, D. A. (2013). Methodology: Dictionary System of Basic Concepts (208 p.). M.: Librokom.

Shishov, S. (2000). School: Monitoring the Quality of Education (206 p.). M.: Pedagogical Societies of Russia.

Simonov, P. V. (1984). Temperament. Character. Lichnost (161 p.). M.: Nauka.

The Decree of the President of the Republic of Uzbekistan (2017). Development Strategy of the Republic of Uzbekistan Adjusted Strategy of Action/Official Publication/Ministry of Justice of the Republic of Uzbekistan (pp. 112-113). Tashkent: Adolat. 